\title{
A MORTE NO COTIDIANO DOS PROFISSIONAIS DE ENFERMAGEM DE UMA UNIDADE DE TERAPIA INTENSIVA*
}

[Death in the daily working routine of nursing professionals in an intensive care unit]

\author{
Ligia Aparecida Palú** \\ Liliana Maria Labronici *** \\ Leomar Albini ${ }^{* * * *}$
}

RESUMO: Trata-se de uma pesquisa qualitativa de abordagem fenomenológica hermenêutica, que teve como objetivo compreender a percepção de morte dos profissionais de enfermagem no seu cotidiano de trabalho em uma Unidade de Terapia Intensiva, de um hospital de ensino da cidade de Curitiba. Foram realizadas 9 entrevistas gravadas, no período de outubro a novembro de 2004 , com a equipe de enfermagem, respeitando a Resolução n 196/96 do Conselho Nacional de Saúde sobre pesquisa envolvendo seres humanos. A análise dos depoimentos se deu mediante três momentos: a descrição, a redução e a compreensão fenomenológica e o tema que emergiu foi: a morte geradora de uma multiplicidade de sentimentos. Evidenciou-se que estes trabalhadores desenvolvem suas atividades cercadas de muita emoção e questionamentos, por não terem sido preparados para trabalhar com a morte, e sim para trabalhar com a vida.

PALAVRAS CHAVE: Morte; Enfermagem; Terapia Intensiva.

\footnotetext{
* Este trabalho é um recorte da monografia intitulada "A Morte no Cotidiano dos Profissionais de Enfermagem de uma Unidade de terapia Intensiva" defendida em novembro de 2004.

** Enfermeira graduada em Enfermagem pela UFPR.

*** Professora Adjunta do Departamento de Enfermagem da UFPR. Doutora em Enfermagem pela UFSC. Membro do Grupo de Estudos Multiprofissional em Saúde do Adulto - GEMSA.

**** Enfermeira. Mestranda em Enfermagem pela UFPR. Membro do GEMSA.
}

\section{INTRODUÇÃO}

A morte constitui um dos maiores enigmas da existência humana, tendo demandado esforços para seu equacionamento ao longo da história do pensamento ocidental (DASTUR, 2002). Ela é considerada como grande divisor das águas na plena constituição dos homens, e de acordo com Martins (2001), é a mais universal das experiências e sua representatividade varia entre as culturas.

Conhecemos a morte somente mediante o processo de morrer dos outros, cujas vivências, jamais nos serão acessíveis em sua real dimensão. Mesmo constituindo-se um fenômeno da vida, sempre despertou grande temor no ser humano, e este sentimento se expressa na dificuldade dele lidar com a finitude, estando presente nas crenças, valores e visão de mundo que cada um traz consigo. Ela é um acontecimento medonho, pavoroso, um medo universal, mesmo sabendose que o homem é capaz de dominá-la em vários níveis (KUBLER-ROSS, 1985). Este sentimento é parte natural do comportamento humano, e nas culturas que a percebem como acontecimento natural, o medo de morrer não está presente. Sócrates, citado por Dastur (2002) sugere que o medo da morte é algo antinatural, pois baseia-se na noção de que se conhece algo que se desconhece.

A relação do ser humano com a morte vêm se transformando através dos séculos, tendo sido considerada como um acontecimento natural, inevitável e perfeitamente aceito. Essa relação anterior de familiaridade com a morte possui hoje na cultura ocidental outra conotação, visto que as 
pessoas sentem-se desconfortáveis perante ela. No mundo moderno a morte está escondida como algo sujo e vergonhoso, sinônimo de absurdo, horror e sofrimento; algo escandaloso e insuportável (IMEDIO,1998). Segundo Thomas citado por Martins (2001), as sociedades modernas tendem a escamotear a morte. Apesar de termos consciência de nossa finitude, falar sobre ela é normalmente considerado um ato mórbido, uma tentativa de mau gosto.

A finitude da vida possui sempre duas representatividades: uma física e outra social, a morte de um corpo (biológica), e a morte de uma pessoa (MARTINS 1983). A morte de uma pessoa adulta significa, normalmente, dor e solidão para os que ficam. Portanto, sob este prisma é apenas a destruição de um estado físico e biológico que ela traz, mas é também o fim de um ser em correlação com um outro. Este vazio por ela deixado não atinge somente as pessoas que conviviam com quem morreu, mas também a toda rede social (RODRIGUES, 1983).

É interessante lembrar que, dentre todos os seres humanos que precisam conviver com os sentimentos provocados pela morte, os trabalhadores da área de saúde encontram-se mais suscetíveis, pois no cenário das instituições hospitalares ela está constantemente presente, motivo pelo qual é tema relevante, porém de difícil abordagem reflexiva no cotidiano da prática de cuidado da Enfermagem, porquanto temos cristalizado em nosso ser o jargão " enquanto há vida há esperança". Neste sentido, vivenciamos um dilema existencial em função do valor negativo dado à finitude, na qual a vida é valorizada e a morte significa a extinção total do ser. $O$ jargão também indica uma obstinação terapêutica, que procura a todo custo, prolongar a vida (HENNEZEL; LELOUP, 1999), motivo pelo qual as instituições de saúde, investem cada vez mais em recursos tecnológicos para reestruturação e recuperação do paciente crítico, ou seja, para manutenção da vida. Nesses ambientes, a morte quase sempre é vista como fracasso, como derrota.

As situações de terminalidade na área da saúde são freqüentes para os profissionais, e muitas vezes, inevitáveis, ficando o trabalhador exposto às mais diversas sensações, porquanto os hospitais são caracterizados como instituições de cura e recuperação, e as UTl's locais reservados para manutenção da vida a qualquer custo. Entretanto, o que se observa nas unidades críticas, em geral, é uma atenção destinada às técnicas, à tecnologia que dá suporte para a manutenção da vida, em detrimento à condição humana e às necessidades emocionais do paciente. Contudo, não podemos esquecer que o ato de cuidar vai muito além do fazer técnico, implica no entrelaçamento das ações de cuidado instrumentais e expressivas, isto é, ligadas à subjetividade do corpo cuidador (LABRONICl, 2002). Assim sendo, espera-se que a equipe de enfermagem, mediante o cuidado profissional, desenvolva suas ações objetivando não somente assistir o ser humano no momento sublime que é seu nascimento, mas comprometer-se com esse momento desconhecido em sua essência, ou seja, o momento da morte.

Boemer citado por Lunardi Filho et al., (2001), afirma que desde a sua formação, o profissional enfermeiro sente-se compromissado com a vida, e é para preservação desta que deverá sentir-se capacitado; sua formação acadêmica está fundamentada na cura, e nela está sua maior gratificação. Assim, quando em seu cotidiano de trabalho necessitam lidar com a morte, em geral, sentem-se despreparados, e tendem a se afastar dela.

Diante do exposto, esta pesquisa teve como objetivo:

Compreender como a equipe de enfermagem de uma Unidade de Terapia Intensiva percebe e convive com a morte em seu cotidiano profissional.

\section{METODOLOGIA}

A compreensão do fenômeno em tela nos levou a escolher um caminho metodológico que possibilitasse a aproximação das vivências da equipe de enfermagem, abarcando o pensar, o sentir e o agir. Desta forma, optou-se pela pesquisa qualitativa, de abordagem fenomenológica hermenêutica, porquanto a pesquisa fenomenológica valoriza os significados que as pessoas atribuem à sua experiência vivida, e que se revelam a partir das suas descrições ou discursos. Consiste num método de investigação 
que enfatiza a complexidade da experiência, na sua totalidade, como ela é realmente vivida. Assim sendo, seu objetivo é descrever os fenômenos vividos pela consciência.

No que se refere à Hermenêutica, trata-se de uma metodologia interpretativa, que permite transformar o distante em próximo, e o estranho em familiar, mediante o discurso orientado pelo desejo do diálogo (POLAK, 1996). A Fenomenologia Hermenêutica deverá, então, decifrar o sentido do texto da existência, esse sentido que precisamente se dissimula na manifestação do dado. (DARTIGUES, 1992).

\subsection{0 processo de obtenção, registro e análise dos discursos}

A pesquisa foi realizada na Unidade de Terapia Intensiva de um hospital de ensino da cidade de Curitiba que é composta por 14 (quatorze) leitos, com a participação de 9 funcionários da equipe de saúde dos quais 2 são enfermeiras, 3 auxiliares e 4 técnicos de enfermagem que atuam no período da manhã. Os entrevistados, na sua maioria, possuíam em média 2 anos de atuação nesta unidade.

Considerando o caráter de subjetividade do estudo, optou-se pela entrevista aberta, constituída com questão elaborada especificamente para este estudo, permitindo maior flexibilidade e possibilitando uma investigação mais ampla sobre as vivências. As entrevistas foram realizadas durante o horário de trabalho, ou seja das 7:00 as 13:00h, no período compreendido entre 01 a 31/ 09/2004. No que diz respeito aos aspectos éticos, o projeto foi encaminhado inicialmente ao Comitê de Ética e Pesquisa da instituição onde o estudo foi realizado para avaliação e parecer. Respeitando a Resolução $n^{\circ}$ 196/96 do Conselho Nacional de Saúde sobre pesquisa envolvendo seres humanos, a entrevista aconteceu após a assinatura do Termo de Consentimento Livre e Esclarecido.

As entrevistas foram gravadas, transcritas e após, analisadas. Considerando a proposta do estudo, a entrevista aberta teve a seguinte pergunta:

Como você percebe e convive com a morte em seu cotidiano de trabalho?

Os dados foram analisados de acordo com a trajetória fenomenológica, proposta por Martins (1992), que consiste em três momentos: descrição, redução e a compreensão fenomenológica.

A descrição fenomenológica é o registro da comunicação do sujeito a respeito de suas percepções sobre o seu mundo-vida, para a qual a consciência está dirigida, atribuindo significados (WOLFF, 1996). "É o momento de apreensão dos significados essenciais do fenômeno, porquanto é na descrição que a essência se manifesta; para elucidar as essências, é preciso desvelar e descrever as estruturas de significado da experiência vivida". (LABRONICl, 2002, p.50)

$A$ redução fenomenológica é o primeiro passo para ver as coisas ditas pelo sujeito como elas se apresentam, livres de pré-julgamentos e preconceitos do pesquisador. Ela tem por objetivo chegar à essência, à natureza própria daquilo que interrogamos, e consiste em determinar, selecionar quais partes da descrição são consideradas essenciais, e aquelas que não são (MARTINS,1992). Deseja-se encontrar exatamente que partes da experiência são verdadeiramente parte da consciência, diferenciando daquelas que são apenas suposições.

A técnica para realizar a redução fenomenológica é chamada "variação imaginativa", e consiste em refletir sobre as partes da experiência que parecem possuir significados cognitivos, afetivos e conativos, imaginando cada parte como estando presente ou ausente na experiência. "Através da comparação no contexto e eliminações, o pesquisador está capacitado a reduzir a descrição daquelas partes que são essenciais para a existência da consciência da experiência" (MARTINS, 1992, p. 60).

A compreensão fenomenológica envolve uma interpretação. "É o momento e a tentativa de desvelar, de especificar possíveis significados na descrição; surge em conjunto com a interpretação e só se torna possível quando o pesquisador assume o resultado como um conjunto de unidades de significado, que mostram a consciência que 0 sujeito tem do fenômeno" (LABRONICl, 2002, p. 52). Segundo Wolff (1996), seleciona-se no discurso do sujeito da pesquisa as asserções mais significativas, de acordo com a percepção do pesquisador, ou seja, aquelas que revelem o significado que a consciência do sujeito atribuiu à sua experiência. Para Martins (1992), a compreensão fenomenológica é o momento de 
tentar especificar o significado que é essencial na descrição e na redução, como uma forma de investigação da experiência.

\subsection{A Trajetória do Estudo}

As entrevistas aconteceram durante o período de trabalho, a partir da disponibilidade dos componentes da equipe. As primeiras dificuldades foram sentidas nesta fase, pois a dinâmica das atividades da UTI, não permitia que surgissem momentos de disponibilidade dos componentes da equipe de modo que pudessem dar seus depoimentos. Apesar do acesso que a autora tem com a equipe, por ter desenvolvido um estágio curricular na mesma unidade, ela encontrou outra dificuldade: a temática. Muitos dos funcionários consideravam difícil falar sobre as situações de morte, alegando não saberem falar sobre o assunto, ou mencionando que o tema exacerbaria sentimentos oriundos de vivências pessoais. Superadas as dificuldades, conseguiu-se realizar 9 entrevistas. As entrevistas foram encerradas porque os dados, considerados em suas convergências e divergências, mostraram-se suficientes para compreensão do fenômeno.

O conteúdo das descrições foi gravado e em seguida transcrito, com objetivo de obter as falas em sua totalidade. Após a transcrição dos discursos prosseguiu-se na trajetória fenomenológica, com a tentativa de compreender as descrições obtidas nos discursos, e os significados que emergiram à consciência de cada sujeito sobre o seu convívio diário com a morte em seu cotidiano de trabalho.

Para chegar a essa compreensão foi necessário prosseguir com o segundo momento fenomenológico, ou seja, o da redução. É oportuno lembrar que para garantir o rigor científico, faz-se necessário "suspender" os conhecimentos anteriores, num retorno as coisas mesmas, anulando qualquer pré-conceito. Assim, considerando a convivência com a morte unicamente como fenômeno, fora colocada entre parênteses ou em suspensão, possibilitando olhála na sua multiplicidade de significados atribuída pela equipe de enfermagem (HUF, 2002). Em seguida, procedeu-se às seguintes fases, propostas por Martins e Bicudo (1989):

$1^{\circ}$ Momento
Fez-se uma leitura das descrições na íntegra, a fim obter o sentido integral dos discursos, numa visão geral daquilo que foi manifestado, para então se familiarizar com a experiência vivida pelo sujeito.

\section{$2^{\circ}$ Momento}

Procedeu-se a várias releituras dos discursos procurando identificar as convergências e as divergências, separando do conjunto dos discursos as expressões significativas para a compreensão do fenômeno. Neste momento, surgiram as unidades de significado.

\section{$3^{\circ}$ Momento}

Traduziram-se as expressões cotidianas do sujeito, contidas nas unidades de significado, para uma linguagem da pesquisadora, que ao buscar a essência do fenômeno, utiliza em seu discurso uma linguagem própria, que sustente o que está se buscando (LABRONICl, 2002).

\section{$4^{\circ}$ Momento}

Sintetizaram-se as unidades de significado sob a forma de uma descrição consistente do fenômeno pesquisado, para então chegar a análise da estrutura do fenômeno.

Ressalte-se que mediante a redução, os conteúdos dos discursos foram destacados e agrupados. Cada segmento de discurso foi numerado para relacionar com o autor, em unidades de significados, conforme se julgou significativas para a elucidação do tema em estudo.

As unidades de significados que surgiram a partir da análise dos discursos, foram identificadas e agrupadas dando origem ao tema central considerado relevante e suficiente para a compreensão do fenômeno:

\section{A morte geradora de uma multiplicidade} de sentimentos.

\section{A COMPREENSÃO DO FENÔMENO}

Da análise dos discursos emergiu o tema "a morte como geradora de uma multiplicidade de sentimentos", e que a convivência com ela no cotidiano laboral só é possível mediante a compreensão articulada destes.

$\mathrm{Na}$ síntese das unidades de significado surgidas nos discursos ingênuos dos sujeitos, diante do convívio com a morte destacam-se: Compaixão; Culpa; Indiferença; Negação; Envolvimento Emocional, Empatia.

A convivência com o processo de morrer 
desperta entre os integrantes da equipe de enfermagem o sentimento da compaixão, principalmente quando este processo é antecedido por um longo período de sofrimento dos pacientes. Waldow citado por Costenaro, et al. (2001), reconhece que o cuidado desperta sentimento de compaixão, solidariedade e ajuda.

A palavra compaixão vem da união da preposição com e o termo paixão, que por sua vez vem do verbo padecer, e tem como significado "estar com". A compaixão consiste em não ter medo do sofrimento do outro e assumi-lo dentro de si, ou seja, mantêm-se o distanciamento certo, para que as pessoas nem se afastem demais e nem se aproximem demais. "Na compaixão, efetivamente toma-se algo do sofrimento alheio, porém sem mergulhar nessa dor que não é nossa". (HENNEZEL; LELOUP, 1999)

Nesta pesquisa, as falas expressam a dificuldade de conviver com o sofrimento e com a morte, que, muitas vezes, por não ser compreendida, está associada ao significado de libertação em relação ao sofrimento e à dor (CEZAR-VAZ, 2001).

“... eu penso que a morte pra eles é um descanso; eu acho que judiam demais e acabam fazendo muito procedimento invasivo. Aquilo lá deve ser muito ruim pro paciente!" (5)

“... porque dependendo da situação que ele tá, às vezes é um alívio né? Igual aquele senhor, imagine a situação dele! Seria melhor que a pessoa mesmo descansasse!" (6)

A convivência com a dor e a aflição que acompanham o processo de morrer, é capaz de modificar a prática do cuidado, na qual o cuidador se torna compassivo perante o sofrimento, mas busca a melhor maneira de ajudar o paciente na hora da sua morte. Portanto, o sentimento de indiferença passa a ser utilizado também como um mecanismo de defesa e proteção contra o processo de finitude, que passa a ser considerado como banal.

As Unidades de Terapia Intensiva na sua grande maioria, são consideradas locais "frios", onde se dispensa uma enorme atenção aos aspectos técnicos em detrimento às questões humanas. Para Costenaro et al., (2001), esta atmosfera distante e impessoal é conseqüência do uso da tecnologia, pois cria um distanciamento entre enfermeiro e paciente mediados pelos aparelhos que desenvolvem neste último, sentimentos de dependência e submissão. Evidenciamos a indiferença nas falas a seguir:

“.... aqui dentro, é como se fosse uma coisa do diaa-dia; ... porque aqui dentro, uma morte pra mim é uma morte a mais! Eu acho que a morte aqui é uma coisa e não tem nada a ver comigo!" (5)

“... estranho, parece que a gente não liga muito! ... parece que é uma coisa comum! Tá doente? Morreu, morreu!" (6)

Estes depoimentos demonstram que o convívio diário com a morte acaba tornando-se normal, e esta passa a ser vista como um fato a mais no cotidiano da unidade. Desta maneira, desritualiza-se a finitude do ser humano, que muitas vezes é tratada por meio de atitudes impessoais.

É comum o ser humano morrer nos hospitais em meio à parafernália tecnológica, que prolonga a todo custo a vida do paciente, mas muitas vezes paradoxalmente, tirando-lhe a dignidade, mesmo nas situações limite, quando já não há qualquer expectativa de reversibilidade. O paciente assim, é observado como objeto clínico. Ele não possui o direito de opinar, como se a vida já não Ihe pertencesse.

Consciente desta realidade, a equipe de enfermagem sente-se culpada em fazer parte de tal sistema que, como já foi frisado, transforma o paciente em objetos, condenando-os a morrer lentamente e sujeitando-o a condições humilhantes e desumanas.

Em relação ao sentimento de culpa, surgiram as seguintes falas:

“... você acaba ajudando a prolongar a morte deles, porque você não quer que ele vá!" (1)

“... tem pacientes que fica meses aí, a gente acaba tendo dó, porque prolongou o sofrimento deles! Porque o egoísmo da gente que acaba prolongando o sofrimento da pessoa ... a gente fica mantendo ela aqui!" (2)

"Sentimo-nos culpados por desejar a morte de alguém, de desejá-la quando a agonia se arrasta indefinidamente" (HENEZEL; LELOUP, 1999, p. 66). O tempo de hospitalização e a certeza da irreversibilidade do quadro clínico dos pacientes, 
muitas vezes despertam o desejo de vê-los morrer. Este desejo coloca o cuidador em uma situação desconfortável ao se questionar sobre como pode chegar a desejar a morte de alguém sem se sentir culpado. Como não enfrentar essa ambivalência de sentimentos? Por um lado se cuida com amor, com carinho e solicitude, e por outro emergem sentimentos de revolta, como o cansaço diante de uma situação que torna a vida impossível.

Atualmente, passamos primordialmente por um período de negação, em que a morte é escondida e falar dela não é de bom tom. Negar é uma forma de não entrar em contato com as experiências dolorosas, e, deste modo, permitese que se viva num mundo de fantasia, onde existe a ilusão da imortalidade. (CASSORLA et al., 1991). Essa realidade reforça o aspecto negativo da morte, dificultando sua aceitação e compreensão. Para Gelain citado por Boemer et al. (1989), os hospitais não aceitam a morte por serem instituições de cura, onde ela se apresenta como possível derrota diante de seus interesses.

O sentimento que tende a excluir a morte do nosso convívio, está expresso nas seguintes falas:

“... você não aceita a morte nunca, você aceita viver, você aceita a conviver, mas aceitar mesmo, você nunca aceita!" (1)

“... nós estamos preparados pra trabalhar com a vida e nunca com a morte! Nós não temos uma coisa cultural mesmo, de nós da América Latina, de nós brasileiros, é de trabalhar com a vida; a gente quer é ver o paciente melhorar!" (9)

Observa-se mediante as falas, que os profissionais se sentem desconfortáveis com a morte em seu cotidiano de trabalho e recusam-se a aceitá-la. A negação surge como uma forma de defesa contra suas próprias fragilidades e limitações. E como tudo que é negado torna-se traiçoeiro, mesmo que inconscientemente, o fenômeno natural do morrer acaba tornando-se um sintomático pesadelo a perseguir a existência humana (HENNEZEL; LELOUP, 1999).

Como citado anteriormente, ao negarem a morte, os homens estão também negando a vida. Weber, citado por Martins (1983), afirma que uma sociedade que perdeu o sentido da morte, perdeu também o sentido da vida. Não se tem clareza da morte porque também não se tem clareza da vida.
Isto nos leva ao envolvimento emocional, que, segundo Travelbee (1982), é considerado a capacidade de transcender-se a si mesmo e interessar-se por outra pessoa, sem que esse interesse nos torne incapazes. Este envolvimento se faz necessário e é considerado um aspecto vital na relação terapêutica, pois promove a empatia, permitindo ao profissional perceber o outro. Ele precisa ocorrer de forma responsável, com os devidos limites a serem respeitados (LUNARDI FILHO et al., 2001).

A empatia, é uma das estratégias do relacionamento humano em que existe uma capacidade de partilhar as experiências do outro (TRAVELBEE, 1982). Esta capacidade ajuda no cuidado ao paciente terminal, pois facilita a comunicação com os paciente, e permite identificar suas necessidades (COSTENARO et al., 2001). Esta interação deve ocorrer no sentido de ajudar o paciente a enfrentar seu sofrimento e ajudá-lo no momento da sua morte. Sobre isso, assim se manifestaram alguns membros da equipe de enfermagem:

“... eles estão conversando e de repente morrem! Agora, dizer que não é pra mim me envolver, não é pra mim chorar! Se você não vai se envolver, não entre na área da saúde... se você não se envolver, o paciente morre e você não se envolve; então deixa ele morrer sozinho!" (1)

“... quando o paciente fica aqui 40/50/60/70 dias, você cria um vínculo com o paciente." (9)

A questão do cuidado prestado no período que antecede o óbito aparece nos discursos da equipe de enfermagem. É certo que durante todo o período de internamento o paciente precisa receber cuidados que the permitam viver com dignidade, ou que diminuam o seu sofrimento nos últimos dias de vida. Este cuidado, muitas vezes, é prestado a pacientes que já se encontram em morte cerebral, exacerbando a angústia sofrida pelos profissionais, que se deparam com corpos inanimados, mas que precisam ser mantidos na sua integridade física.

Cuidar do ser humano que está morrendo nos faz refletir sobre a fragilidade da vida, e muitas vezes, coloca aquele que cuida frente às suas impotências. Neste contexto, emergem os maiores conflitos para a equipe, que apesar de prestar toda 
assistência possível, percebe a vida esvair-se lentamente, diante da morte que não pode evitar. Aqui se está diante da essência da enfermagem, expressa nas seguintes falas:

“... pra fazer um bem-estar pro paciente, tanto em vida quanto pra morte: hoje eu penso assim também: você tem que promover o bem estar pro paciente mesmo na hora da morte!" (4)

“... uma paciente de 41 anos, que está em morte cerebral, como é que gente trabalha isso? ... tem que tomar banho, tem que se alimentar, mudança de decúbito, ... o coração ainda bate ...” (9)

O cuidado que caracteriza o trabalho da enfermagem deve ser uma experiência vivida com o objetivo de promover a humanização, a recuperação da saúde, uma melhor qualidade de vida dos pacientes e uma morte digna, que são considerados em sua plena humanidade (COSTENARO et al., 2001).

Com base nos dados obtidos, percebe-se que a equipe considera o cuidado humano como essencial para que se garanta uma assistência de enfermagem adequada, e isso não exclui até mesmo os momentos em que a vida daqueles que estão sendo cuidados está chegando ao fim.

\section{CONSIDERAÇÕES FINAIS}

Iniciei este estudo propondo-me a lançar um olhar atento para o profissional de enfermagem que tem a morte como companheira em seu cotidiano de trabalho. Trabalhar com essa temática proporcionou reflexões que transcendem o aspecto biológico da morte, no qual ela é considerada apenas como a cessação das funções fisiológicas ou a falência de um órgão vital.

Observei mediante os discursos dos sujeitos que, apesar de perceberem a morte como alívio para o sofrimento dos pacientes, a equipe tem uma forte tendência a negá-la, pois possuem a consciência de que estão trabalhando pela vida e não pela morte, e neste sentido recusam-se a aceitá-la. Esta compreensão da morte como fracasso, está reforçada pela própria formação do profissional, quando, neste momento, se deixam de abordar e promover discussões referentes às concepções e aos sentimentos sobre a morte e o morrer.
O sentimento de negação não impede que os profissionais procurem conviver de forma aceitável com o processo de morrer dos pacientes. Em seus relatos, eles demonstraram ver a morte como fato natural, mas para isso desenvolvem outros sentimentos como a imparcialidade, que também pode ser considerada como uma forma de defesa frente à dor e, ao sofrimento que terminam com a morte. Para a equipe esse "distanciamento" é necessário a fim de evitar prejuízos nos aspectos psicológicos e emocionais dos trabalhadores de saúde. Com relação a este aspecto, pude observar uma contradição presente nas falas, pois apesar de alguns profissionais se mostrarem indiferentes com o morrer do outro, mostraram também ser impossível cuidar de alguém sem envolver-se. Quando os pacientes permanecem internados por um longo período de tempo, acontece o que se chama de envolvimento emocional do cuidador, o qual pode ser considerado como a capacidade de transcenderse a si mesmo e interessar-se por outra pessoa.

Por fim, ficou evidente que não se pode falar sobre a morte, sem se falar sobre a vida, mesmo que esta esteja se esvaindo, assim como não se pode falar sobre enfermagem sem se falar de cuidado. Cuidar de quem está morrendo - ou que já morreu - é considerada uma tarefa difícil, na qual são exacerbados sentimentos oriundos de vivências pessoal e familiar de quem cuida. Compreendo, então que estes trabalhadores desenvolvem suas atividades cercadas de muita emoção e questionamentos, uma vez que não foram preparados para trabalhar com a morte, e sim para trabalhar com a vida.

Neste sentido, este trabalho demonstra a necessidade de se rever as questões relacionadas com a morte e o morrer na formação profissional, pois observa-se que, neste período existe uma lacuna em relação a esta temática, deixando os trabalhadores de saúde despreparados para trabalharem com essa realidade. Vale lembrar da importância de se promoverem debates e reflexões a respeito das situações de morte nestes ambientes em que ela se faz presente. As questões éticas também podem ser abordadas, quando a luta incessante contra a morte pode se tornar uma interessante fonte de capitalização.

ABSTRACT: It is a qualitative research with a 
phenomenological-hermeneutic approach, which objectified to apprehend the perception of death for nursing professionals along their daily working routine in an Intensive Care Unit in a University Hospital. Nine (9) recorded interviews with a nursing team were carried out between October and November/ 2004. The interviews conformed to Resolution N.196/96 of National Health Council on research involving human beings. The analysis of the accounts went through three steps: description, reduction and phenomenological understanding. It was pointed out that living surrounded by death can bring about a multitude of feelings, such as: compassion, guilt, detachment, denial, emotional involvement/ empathy. It was evidenced that those professionals perform their tasks surrounded by a lot of emotion and inquiries as they have not been prepared to cope with death but work with life.

KEY WORDS: Death, Nursing, Intensive Care.

\section{REFERÊNCIAS}

BOEMER, M. R. et al. A idéia de morte em unidade de terapia intensiva - análise de depoimentos. Revista Gaúcha de Enfermagem, Porto Alegre, v.10, n.2. p.8-14, jul.,1989.

CASSORLA, M. S. (Org). Da morte: estudos brasileiros. Campinas: Papirus, 1991.

CEZAR-VAZ, M. R. et al. A certeza incerta da morte e suas metáforas na situação de acometimento de AIDS - tuberculose. Texto \& Contexto Enfermagem, Florianópolis, v.10, n.3, p.82 - 100, set /dez. 2001.

COSTENARO, R. G. S. (Org.). Cuidando em enfermagem: pesquisa e reflexões. Santa Maria: UNIFRA, 2001.

DARTIGUES, A. O que é a fenomenologia? São Paulo: Moraes, 1992.

DASTUR, F. A morte, ensaio sobre a finitude. Rio de Janeiro: Difel, 2002.

HENNEZEL, M. ; LELOUP, J. Y. A arte de morrer. Petropolis: Vozes, 1999.
HUF, D. D. A face oculta do cuidar. Rio de Janeiro: Mondrian, 2002.

IMEDIO, E. L. Enfermería en cuidados paliativos. Madri: Panamericana, 1998.

KÜBLER-ROSS, E. Sobre a morte e o morrer. São Paulo: Martins Fontes, 1985.

LABRONICI, L. M. Eros propiciando a compreensão da sexualidade das enfermeiras, Florianópolis, 2002. Tese (Doutorado em Enfermagem) - Setor de Ciências da Saúde, Universidade Federal de Santa Catarina.

LUNARDI, W. D. et al. Percepções e condutas dos profissionais de enfermagem frente ao processo de morrer e morte, Texto e Contexto Enfermagem, Florianópolis, v. 10, n. 3, p. 60-81, 2001.

MARTINS, G. Laços atados - a morte do jovem no discurso materno. Curitiba: Moinho do Verbo, 2001.

MARTINS, J. Um enfoque fenomenológico do currículo: educação como poiésis. São Paulo: Cortez, 1992.

MARTINS, J.; BICUDO, M. A. V. A pesquisa qualitativa em psicologia: fundamentos e recursos básicos. São Paulo: Moraes, 1989.

MARTINS, J. S. (Org.). A morte e os mortos na sociedade brasileira. São Paulo: Hucitec, 1983.

POLAK, Y. N. S. A corporeidade como resgate humano na enfermagem. Florianóplis, 1996. Tese ( Doutorado em Enfermagem) - Setor de Ciências da Saúde, Universidade Federal de Santa Catarina.

RODRIGUES, J. C. Tabu da morte. Rio de Janeiro: Achimé, 1983.

TRAVELBEE, J. Intervencion en enfermeria psiquiátrica. Philadelphia: FA, 1982. 
WOLFF, L.D.G. A compreensão da experiência de ser cuidadora de enfermagem em uma unidade de terapia intensiva pediátrica. Florianópolis, 1996, Dissertação (Mestrado em Enfermagem) - Setor de Ciências da Saúde, Universidade Federal de Santa Catarina.

ENDEREÇO DAS AUTORAS:

Rua São Pedro do Ivaí, 151

São José dos Pinhais/PR 